\title{
Релаксация двумерного электронного газа по энергии и импульсу в гетероструктурах AlGaAs/InGaAs/GaAs с донорно-акцепторным легированием при взаимодействии с акустическими фононами
}

\author{
Протасов Д.Ю. ${ }^{1,2}$, Бакаров А.К. ${ }^{1}$, Торопов А.И. ${ }^{1}$, Журавлев К.С. ${ }^{1}$ \\ ${ }^{1}$ ИФП СО РАН, 630090, Новосибирск, пр. Ак. Лаврентьева, 13 \\ ${ }^{2}$ Новосибирский государственный технический университет, 630073, Новосибирск, пр- m Карла \\ Маркса, 20
}

DOI 10.34077/Semicond2019-238

Донорно-акцепторное легирование гетероструктур AlGaAs/InGaAs/GaAs позволяет получать двумерный электронный газ (ДЭГ) высокой плотности (до $(4 \div 5) \times 10^{12} \mathrm{~cm}^{-2}$ ) без появления паразитной параллельной проводимости по области дельта-слоев [1]. В таких гетероструктурах заполнены первые да уровня размерного квантования, что приводит к появлению особенностей релаксации электронов по энергии и импульсу при взаимодействии с акустическими фононами [2]. В данной работе исследуется взаимодействие ДЭГ с акустическими фононами в гетероструктурах $\mathrm{AlGaAs} / \mathrm{InGaAs} / \mathrm{GaAs}$ с донорно акцепторным легированием, концентрация электронов на верхнем и нижнем уровнях отличается менее, чем в два раза, и энергетический зазор между уровнями достаточно велик и составляет $30 \div 40$ мэВ. Для увеличения роли рассеяния на акустических фононах влияние рассеяния на ионизированных донорах было уменьшено разделением каждого из дельтаслоёв на два и использованием сверхрешетки $\mathrm{AlAs} / \mathrm{GaAs}$ в качестве спейсера. Для разделения вкладов рассеяний на деформационной моде акустических фононов и на неоднородностях сплава была выращена серия гетероструктур $\mathrm{AlGaAs} / \mathrm{InGaAs} / \mathrm{AlGaAs}$ с разным содержанием индия $y_{\text {in }}$ в КЯ (от $18 \%$ до $0 \%$ ) и одинаковым уровнем легирования. Вклад рассеяния на деформационной моде акустических фононов определялся из анализа температурных зависимостей подвижности дЭГ, измеренных в диапазоне 4.2 К - 77 К.

Увеличение $y_{i n}$ привело к возрастанию концентрации ДЭГ от $2.2 \times 10^{12} \mathrm{~cm}^{-2}$ до $3.9 \times 10^{12} \mathrm{~cm}^{-2}$ и к уменьшению подвижности от $7900 \mathrm{~cm}^{2} \mathrm{~B}^{-1} \mathrm{c}^{-1}$ до $7500 \mathrm{~cm}^{2} \mathrm{~B}^{-1} \mathrm{c}^{-1}$ при комнатной температуре. Анализ температурной зависимости подвижности показал, что рассеяние на деформационном потенциале усиливается при увеличении $y_{i n}$. Константа деформационного потенциала при этом приблизительно в два раза меньше используемого в литературе значения и её величина возрастает при увеличении $y_{i n}$.

Для исследования процессов энергетической релаксации величины электронной температуры определялись методом осцилляций Шубникова-де Газа (ШдГ). Осцилляции ШдГ измерялась с помощью сверхпроводящего соленоида, погруженного в жидкий гелий. Электронная температура $T_{e}$ ДЭГ регулировалась силой постоянного тока, пропускаемого через холловские структуры.

Осцилляции ШдГ в исследуемых гетероструктурах содержат несколько частот: частоты $f_{1}$ и $f_{2}$ связаны с первой и второй подзонами; комбинационные частоты $f_{1} \pm f_{2}$, обусловлены переходами между уровнями Ландау соседних подзон; также наблюдаются частоты, кратные $f_{l}$. Нагрев электрическим током приводит к быстрому подавлению частоты $f_{1}+f_{2}$ и кратных частот. Частоты $f_{1}$ и $f_{2}$ затухают более медленно, а частота $f_{1}-f_{2}$ уменьшается весьма незначительно при увеличении $T_{e}$. Из анализа зависимости амплитуды Фурье-преобразования осцилляций ШдГ с частотами $f_{1}$ и $f_{2}$ было найдено, что при приложении электрического поля с напряженностью от $\sim 0.1 \mathrm{~B} / \mathrm{cm}$ до $\sim 3 \mathrm{~B} / \mathrm{cm}$, электронная температура возрастает от 4.2 К до $20 \div 30 \mathrm{~K}$.

[1] D.Yu. Protasov and K.S. Zhuravlev, Solid State Electronics, 129, 66 (2017).

[2] E. Tiras et al, Phys. Rev. B, 64, P. 085301 (2001). 